\title{
Perceptions of Cyberbullying Amongst Teachers and Senior Management
}

\author{
Loreto Mattioni, Vanessa A. Green, Flaviu Hodis and Tegan E. Lynch
}

\begin{abstract}
Cyberbullying has become a serious problem that can have significant long-term effects on students' mental health and academic outcomes. Given that most cyberbullying experiences involve individuals from a student's school environment, it is important to examine the views of school staff on cyberbullying to develop appropriate prevention and intervention strategies. Positioned within the social-ecological framework, where interactions are facilitated by technology, this study explored teachers' and senior managers' perceptions towards cyberbullying. An online anonymous survey yielded 210 responses. The results showed that most respondents understood what behaviours constituted cyberbullying. However, many were unlikely to identify social exclusion as a component of cyberbullying. They perceived cyberbullying as conducted by students across all age groups, but mainly by girls. Senior managers were more likely than teachers to report low frequencies of cyberbullying and thus, not surprisingly, less likely than teachers to perceive cyberbullying as a problem in their schools. Finally, the majority of staff wanted to receive training on how to deal with cyberbullying.
\end{abstract}

\section{Keywords:}

cyberbullying, perceptions, principals, schools, teachers, techno-subsystem

\section{Research paper}

\section{INTRODUCTION}

Recent technological developments and the increasing proliferation of information and communications technology (ICT) have contributed to the development of a relatively new form of bullying: cyberbullying. Cyberbullying is defined as "an aggressive, intentional act carried out by a group or individual, using electronic forms of contact, repeatedly and over time against a victim who cannot easily defend him or herself" (Smith \& Slonje, 2010, p. 249). Studies have shown that students involved in cyberbullying are a subset of those involved in traditional bullying (Maher,
2008; Salmivalli, Sainio \& Hodges, 2013; Ybarra \& Mitchell, 2004) and therefore victims of cyberbullying may also experience other forms of bullying from individuals in their school environment. The effects of cyberbullying, and other forms of bullying, are serious, with links to severe psychological, social and mental health problems (Cross et al., 2009, Smith, Steffgen \& Sittichai, 2013).

To understand the impact of bullying and how it develops, Bronfenbrenner's social-ecological model has been adapted by Swearer and Espelage (2004). In particular, through their framework, they emphasize that different contexts (individuals, family, peer groups, school, community, and culture) will influence the engagement, or non-engagement, in bullying and victimization behaviours. Within the social-ecological approach to bullying, the techno-subsystem is a type of microsystem that encompasses interactions facilitated by technology and is particularly covert (Johnson \& Puplampu, 2008). Accordingly, incidences of cyberbullying that occur within this techno-subsystem can affect, and be affected, by all other systems in the child's life. Another system that can have a significant impact on the development of cyberbullying is the school climate; the tone of which is often set by the adults in the environment (Carroll-Lind, 2009; Espelage, Low \& Jimerson, 2014; Espelage \& Swearer, 2010; Holt \& Keyes, 2004; Huang \& Chou, 2013). If the adults are not familiar with the current social media context, then they may be less likely to understand and address cyberbullying (Spears \& Zeederberg, 2012).

There has been a recent focus on the importance of classroom environments to the perpetuation of bullying, with studies showing that teacher beliefs can have an impact on the prevalence of bullying and how incidents are dealt with (Espelage, Low \& Jimerson, 2014; Oldenburg et al., 2015; Stauffer, Heath, Coyne \& Ferrin, 2012). As most cyberbullying is reported as coming from students in the same class or year group (Smith et al., 2006), it is therefore important to examine the school climate and, in particular, the perceptions of school staff with regard to cyberbullying to inform and develop appropriate prevention and intervention strategies. 
One study that has investigated teachers' perceptions of cyberbullying involved 66 USA high school teachers who were asked about the effect cyberbullying had on students and about specific intervention and prevention strategies. The authors found almost 60 percent of teachers were against or unsure about implementing a formal bullying prevention programme in their school (Stauffer et al., 2012). The researchers suggest that this view could be because the participants did not see bullying as a problem in their school. In addition, a study conducted in Canada, looking at the perspectives of teachers toward traditional forms of bullying, identified that teachers' perceptions can be influenced by an awareness of bullying prevalence (Craig, Henderson \& Murphy, 2000). For example, as students are less likely to report cyberbullying than other forms of bullying (Smith et al., 2008) and when they do report it, they rarely provide the information to teachers (Huang \& Chou, 2013), it is possible that teachers may not be privy to the prevalence of cyberbullying and may therefore not see it as a problem in their school.

It appears that the type of bullying can also have an influence on the relative importance it is given. For example, teachers do not necessarily view relational aggression as a form of bullying and are less likely to intervene with this type of bullying (Boulton, 1997; Craig et al., 2000). Cross et al., (2009) found considerable variability in their sample of teachers; with 20 percent stating that they did not know whether most teachers would consider students forwarding other student's private emails, pictures and videos as a form of bullying. These findings suggest that it is important to investigate the perceptions of teachers with regard to how often cyberbullying is brought to their attention, and what behaviours they think constitute cyberbullying.

It would seem that perceptions of bullying can differ depending on what position an individual holds within the school environment. For example, in the USA, Newgent et al. (2009) conducted a comparative study on the perceptions of bullying in schools among students, teachers, parents, counsellors and principals. The researchers found that senior managers under-estimated the extent to which bullying behaviour was a problem in their school when compared to estimates made by teachers. However, there were only four participating principals in this study and given that it is usually senior management who are responsible for providing leadership around school policy, programmes and training, there is a need to investigate the perceptions of cyberbullying held by senior school staff. To date, however, relatively little attention has been given to the perceptions of senior management toward cyberbullying.

Regarding the gender of students implicated in bullying there is considerable evidence to suggest that boys are more likely to be involved in bullying than girls (Olweus, 1997). However, there is also some disparity in the current research on cyberbullying (Smith, Steffgen \& Sittachai, 2013). Some studies have found that girls are more likely than boys to be involved in cyberbullying (Marsh, McGee, Nada-Raja \& Williams, 2010; Rivers \& Noret, 2010), whereas other studies have found that males were more likely than females to be involved (Calvete, Orue, Estévez, Villardon \& Padilla, 2010; Li, 2008; Heiman \& Olenik-Shemesh, 2013; Salmivalli \& Pöyhonöen, 2012). Furthermore, Ybarra and Mitchell (2004) and Smith et al., (2008) found few or no gender differences. Despite different findings with regard to gender, most studies have shown that cyberbullying is more likely to occur in high school rather than primary school, and peaks around 13-15 years (Ybarra and Mitchell, 2004; Raskauskas and Stoltz, 2007; Smith et al., 2008; Smith, et al., 2013; Tokunaga, 2010). However, there appears to be a lack of recent research that identifies school staff perceptions of the gender and age characteristics of students involved in cyberbullying, particularly within primary school age ranges.

Some researchers have focused on the need for training of teachers to address cyberbullying incidents. In one recent study of 45 Irish post-primary school principals who were asked about their methods of addressing bullying and cyberbullying (Corcoran \& McGuckin, 2014), the researchers found that while many respondents aimed to provide training to teachers regarding cyberbullying, there was great disparity with regard to the training approaches. Furthermore, Li (2008) found pre-service teachers were concerned about cyberbullying but had little confidence in being able to identify (13.1 percent) or manage (11.1 percent) it. In addition, only 3.3 percent of pre-service educators thought that they had been prepared within their university education to manage cyberbullying. Those studies suggest that principals as well as pre-service teachers have identified the need for further training around cyberbullying. However, there appears to be a lack of current research that identifies in-service teachers' perceptions of the need for training around cyberbullying.

When considered within Swearer and Espelage's (2004) social-ecological framework of bullying, cyberbullying appears to represent a unique aspect of the school environment as it occurs within the 
somewhat covert techno-subsystem. In order for effective intervention and prevention strategies to be developed it is important to ascertain the perceptions of those adults who are responsible for setting the tone of the school climate. Therefore, the aim of this study was to examine the perceptions of New Zealand teachers and senior school staff toward cyberbullying with regard to what constitutes cyberbullying, its prevalence, who is involved, and whether there is a need for specific training.

\section{METHOD \\ Participants}

An anonymous online self-report questionnaire on cyberbullying was used as a data collection instrument. An introductory email explaining the survey was sent to the principals of 2,392 New Zealand schools. They were invited to respond to the survey and asked to forward the survey to their senior managers and teaching staff so that they might also have an opportunity to participate in the survey. This introductory email provided a URL link to the survey website.

\section{Measures}

Relevant questions from the 'Bullying in New Zealand Schools' online survey (Green, Mattioni \& Prior, 2012) provided the focus of the current study. In particular, demographic questions asked respondents about their gender, school type (e.g. co-educational, decile, primary), length of experience teaching, and position within the school. Six of the questions that were related specifically to cyberbullying are presented in this report and were developed using a combination of original questions from three previously published surveys; the Child Health Centre Survey (Cross et al., 2009), the School Climate Survey (Ontario Ministry of Education, 2009), and Teachers Perceptions about Cyberbullying Questionnaire (Li, 2008). In particular for the first question, participants were asked whether they believed cyberbullying was a problem in their school by indicating their response on a 5-point Likert type scale ( 1 = Strongly Disagree, 5 = Strongly Agree). For the second question participants were asked how often cyberbullying was brought to their attention and they were provided with the following five options; not once in four weeks, one or twice in four weeks, once a week, more than once per week, and don't know. For question three the participants were provided with a list of nine examples (e.g. students sending threatening emails; students deliberately ignoring or leaving others out of events over the internet) and asked to indicate their agreement (i.e. yes, no, or don't know) about whether or not these constituted a form of cyberbullying. These items were based to a large extent on the questionnaire used to measure covert bullying in the Cross et al., (2009) study. The fourth question asked respondents to indicate (based on their own personal experience and perspective) the gender of students implicated in cyberbullying (i.e. mainly boys, equal number of boys and girls, mainly girls). The next question asked respondents to indicate (again based on their personal experience and perspective) what age children engaged in cyberbullying (i.e. mainly children 9-10 years, mainly younger adolescents 11-14 years, mainly older adolescents 15-18 years, or students across all age groups). Finally, respondents were asked to indicate (i.e. yes, no, or not sure) whether they think teachers need training to deal with and counteract the effects of cyberbullying.

\section{RESULTS}

\section{Demographics}

As shown in Table 1, of the 210 participants, 112 (53\%) were senior managers (i.e. principals and deputy principals) and 98 (47\%) were teachers. In particular, 32 percent of the participants were female teachers, followed by female senior managers $(27 \%)$, male senior managers (26\%), and male teachers (15\%). The level of experience of school staff was grouped into three categories; early career $(0-6$ years), middle career ( 7 - 20 years) and later career $(20+$ years $)$. Of the participants, $35(17 \%)$ were classified as early career school staff, 78 (37\%) reported being middle career school staff, and 97 (46\%) as later career school staff.

Results showed that over half of the participants worked in primary schools (53\%), followed by almost a third in secondary schools (32\%). Only 11 percent of the participants worked in a school for children 11-12 years or schools targeted at children from 11-18 years. In addition, most of the participants worked in coeducational schools (93\%). Only 9 respondents (4\%) worked in an all-female school and 6 respondents (3\%) worked in an all-male school. Relative to the number of schools who received the orginal email, 210 participants was a low response; however, although senior management were over-represented in this sample, it appears to be a representative sample of New Zealand teachers with regard to gender and school type (Education Counts, n.d.).

Table 1

Participants' Position Within the School as a Function of Gender and Level of Experience in Schools

\begin{tabular}{|c|c|c|c|c|c|c|}
\hline \multicolumn{7}{|c|}{ Position within the School } \\
\hline & \multicolumn{3}{|c|}{ Teachers $(n=98)$} & \multicolumn{3}{|c|}{ Senior Managers $(n=112)$} \\
\hline & Early & Middle & Later & Early & Middle & Later \\
\hline Male & 7 & 15 & 9 & 5 & 13 & 36 \\
\hline Female & 19 & 30 & 18 & 4 & 20 & 34 \\
\hline Total & 26 & 45 & 27 & 9 & 33 & 70 \\
\hline
\end{tabular}




\section{Perceptions of Cyberbullying}

Teachers and senior managers were asked about what behaviours they considered to be cyberbullying. In particular, a list of nine examples of cyberbullying behaviours were presented to school staff. There was considerable agreement with between 81 percent and 85 percent of staff saying 'yes' to eight of the nine statements. The only type of cyberbullying where there was some disagreement was 'ignoring or leaving others out of events over the Internet'. Although slightly more than half of the school staff surveyed (58\%) considered that behaviour as being cyberbullying, 20 percent did not consider it as a component of cyberbullying, and the remaining individuals were unsure if it would be considered cyberbullying.

To assess teachers' and senior managers' perceptions of the extent of cyberbullying among students, the staff were asked to indicate their agreement with the following statement: 'Cyberbullying is a problem among students at our school'. Although 79 participants (38\%) did consider cyberbullying to be a problem in their school, 90 (43\%) participants did not consider cyberbullying as a problem in their school, and 39 respondents $(19 \%)$ neither agreed nor disagreed with the statement. Overall, most of the participants did not consider cyberbullying as a problem in their schools or were unsure about its occurrence $(M=2.79, S D=1.27)$. The results revealed a significant difference however between teachers $(M=3.24, S D=1.14)$ and senior managers $(M=2.39$, $S D=1.24) ; Z=4.65, p=.001$. These results suggest that teachers were more likely to report cyberbullying as a problem in schools than senior managers.

To assess school staff's perceptions of the extent of cyberbullying among students, participants were asked to think about the past four weeks and indicate on a five point scale the frequency with which cyberbullying was brought to their attention. More than half of the participants (54\%) reported that cyberbullying had not been brought to their attention in the last four weeks. Approximately 20 percent reported that cyberbullying had been brought to their attention once or twice in four weeks and 15 percent of the participants reported that cyberbullying had been brought to their attention at least once per week over the last four weeks.

Given the finding that teachers were more likely than senior managers to report that cyberbullying was a problem in schools, it was hypothesised that senior managers may be less likely to be aware of cyberbullying incidents than teachers. A chi-square test of independence was performed to examine the relation between the frequency of cyberbullying reported and position within the school. The relation between these variables was significant, $x^{2}(4, N=$ $202)=16.54, p=.002$. As shown in Table 2, 72 $(67 \%)$ senior managers stated that they had not had an incident of cyberbullying reported to them in the last four weeks compared to $38(40 \%)$ teachers. In addition, $40(42 \%)$ teachers compared to 30 $(27 \%)$ senior managers had at least one incident of cyberbullying reported to them in the last four weeks. Although there is research to suggest that students rarely inform teachers about cyberbullying, it is plausible that given their front-line position, teachers are more likely than senior staff to be approached about the issue. This difference, however, does highlight the possibility that if a senior staff member is not told about the issue (even indirectly by a teacher) they may not see it as a problem in their school.

Table 2

Frequency of Cyberbullying Reports in the Past Four Weeks as a Function of School Position

\begin{tabular}{lcccc}
\hline \multirow{2}{*}{ Cyberbullying Frequency } & \multicolumn{4}{c}{ Position within the School } \\
\cline { 2 - 5 } & \multicolumn{2}{c}{$\begin{array}{c}\text { Teacher } \\
(\mathrm{n}=94) *\end{array}$} & \multicolumn{2}{c}{$\begin{array}{c}\text { Senior Manager } \\
(\mathrm{n}=108)^{*}\end{array}$} \\
\hline & $\mathrm{N}$ & $\%$ & $\mathrm{~N}$ & $\%$ \\
\hline Not once in 4 weeks & 38 & 40 & 72 & 67 \\
\hline Once or twice in 4 weeks & 21 & 22 & 18 & 17 \\
\hline Once a week & 10 & 11 & 8 & 7 \\
\hline More than once per week & 9 & 10 & 4 & 4 \\
\hline Don't know & 16 & 17 & 6 & 5 \\
\hline * some respondents didn't answer this question
\end{tabular}

Teachers and senior managers were asked if cyberbullying was conducted by mainly boys, equal number of boys and girls, or mainly girls. The results showed that most of the participants $(65 \%)$ reported they perceived cyberbullying as conducted mainly by girls, while 34 percent of the participants said they perceived cyberbullying as conducted by equal numbers of boys and girls. Respondents were also asked about the ages of children involved in cyberbullying. Results showed that many participants (44\%) reported they perceived cyberbullying as being conducted by students across all age groups. In addition, 39 percent of the participants perceived cyberbullying as being conducted by mainly younger adolescents, while 17 percent reported they perceived cyberbullying as being conducted mainly by older adolescents. However, some caution is needed in interpreting these findings given that the respondents were from across the sector and would thus have a diverse range of experiences with regard to their perceptions of cyberbullying. 
Finally, school staff were also asked if they thought teachers needed training to deal with and counteract, the effects of cyberbullying. Results show that 75 percent of principals and 71 percent of teachers perceived a need for training, while only 10 percent of principals and 6 percent of teachers thought they did not need training.

In summary the results from this study demonstrate that in terms of who is involved, teachers and senior management hold similar perceptions with regard to the need for training, what constitutes cyberbullying, as well as the gender and age of those involved. However, teachers were more likely than senior managers to report that cyberbullying was a problem in the school and that cyberbullying had been brought to their attention at least once per week in the last four weeks.

\section{DISCUSSION}

The results of this study were similar to previous literature in that school staff were likely to consider most of the listed phrases as types of cyberbullying, including the use of technology to upload and deliver inappropriate messages and posts (Cross et al., 2009). However, a large number of the participants in the present study did not view 'ignoring or leaving others out of events over the Internet' as cyberbullying. Again, this finding is similar to previous studies that have found school staff are less likely to identify social exclusion as a type of bullying (Boulton, 1997; Craig et al., 2000; Cross et al., 2009). With regard to who is more likely to cyberbully, the present study found that over half of the respondents believed it was more likely to be girls than boys. This finding is consistent with a view put forth by Smith (2014) who suggests that "overall there is relatively greater involvement of girls in cyberbullying" (p. 85). This is particularly relevant if we view cyberbullying as similar to relational bullying (Wang, lannotti \& Nansel, 2009).

The present study found that school staff perceived cyberbullying as being conducted by students across all age groups (i.e. 9-18 years old). However, previous research which investigated the characteristics of students implicated in cyberbullying (albeit from the students' point of view) found that older students were more often implicated in cyberbullying than younger students (Ybarra \& Mitchell, 2004; Raskauskas \& Stoltz, 2007; Smith et al., 2008). This discrepancy could be attributed to a number of factors. First, the current study is one of the first that has attempted to elucidate school staff's perceptions of the ages of students implicated in cyberbullying and included primary school age ranges. Second, the present study was conducted some years later than the previous ones, so it is more likely that young children have more access to technology and therefore the opportunity to be involved in cyberbullying. Finally, given that the staff in the present study were located in a range of settings and would have been teaching different age groups, this may have influenced their views and thus future research could include a more refined way of assessing these perceptions.

Although the majority of school staff in the present study were concerned about cyberbullying, most did not consider it to be a problem in their school. When this is considered in the context of infrequent reporting, this finding is perhaps not surprising. It could be argued that cyberbullying is not a problem in schools because it frequently occurs outside of school hours. Perhaps a more accurate question would be: Is cyberbullying a problem amongst school-aged children? However, there is considerable debate in the literature with regard to prevalence of cyberbullying, with some authors suggesting a prevalence as low as 1-2 percent and others reporting figures as high as 43 percent (Raskauskas, Gregory, Harvey, Rifshana \& Evans, 2010). Frisen et al. (2013) highlight the importance of recognising that prevalence can be influenced by a number of factors including the operationalisation of the term cyberbullying (e.g. vague vs specific definitions) as well as the reference period used in measuring the concept (e.g. students can be asked whether they have experienced cyberbullying in the last year vs the last month).

Given the existence and relative importance of the techno-subsystem that permeates the lives of pre-adolescents and adolescents, a tendency to under-report cyberbullying is understandable. Therefore, another possible reason for the relatively low reporting of cyberbullying is that students may be reluctant to report cyberbullying to school staff (Huang \& Chou, 2010; Smith et al., 2008) possibly because of the consequences. For example, one study found most of the students surveyed believed the school could do nothing and students might be restricted in their use of technology ( $\mathrm{Li}, 2010)$. Furthermore, there is some evidence demonstrating that young people are likely to spend time hiding their online identity from their parents (Livingstone \& Bober, 2005).

The finding in the current study that teachers' were less likely to view social exclusion as a type of cyberbullying mirrors previous results. For example, it has been found that a significant proportion of teachers view social exclusion by peers less seriously and are less likely to intervene than in the cases of verbal and physical aggression (Yoon \& Kerber, 
2003). Therefore, if social exclusion is not necessarily seen as a type of bullying by adults (whether in person or over the internet) then the same may be true of students. Yet there is evidence to suggest, through the use of functional magnetic resonance imaging (fMRI), that the damage caused by this type of bullying can be equivalent to the experience of physical pain (Eisenberger, Lieberman \& Williams, 2003).

We predicted that perceptions of cyberbullying may depend on who was being asked. The findings revealed that although most teachers and senior managers were consistent in how they understood or viewed cyberbullying, there were some discrepancies between them with regard to awareness. While school staff who participated in the current study reported low frequency of cyberbullying among their students, teachers were more likely than senior managers to perceive cyberbullying as a problem in their schools and to report higher frequencies of cyberbullying in their schools. These findings are similar to those of Newgent et al. (2009) who found that teachers' ratings of bullying were more similar to students' ratings than they were to principals' ratings, who generally did not characterize bullying as a problem in their schools.

One of the limitations of this study is the small sample size relative to the number of schools who were contacted. However, it is important to highlight the value of this preliminary study as one of the first to survey teachers and senior managers about cyberbullying. The current study used a self-report questionnaire to elicit school staff's perceptions about cyberbullying. Future studies could present school staff with hypothetical scenarios to assess their views on cyberbullying. According to Poulou (2001), advantages of using vignettes based on real situations include their unobtrusive ability to capture complex thoughts about sensitive issues, such as the case with bullying and/or cyberbullying.

By viewing the results of the current study within the social-ecological framework, a number of important applied implications may be noted. For example, according to this framework, the school climate can have a positive or negative effect on cyberbullying and as the climate is strongly influenced by the perceptions and attitudes of school staff, their understanding of the issue matters. Given the vast majority of children who are cyberbullied are also experiencing traditional bullying, it is important for teachers and senior managers to understand the connections between the different forms of bullying and the underlying peer related causes (Salmivalli \& Pöyhonöen, 2012). Furthermore, since cyberbullying behaviours are largely influenced by individual factors and social environments, interventions also need to target those elements by implementing a whole-school approach that includes the parents as partners (Limber, Kowalski \& Agatston, 2008).

Another implication is the need to better-understand the techno-subsystem, which has been proposed as part of the child's social ecology by Johnson and Puplampu (2008). It has emerged as a new setting to prevent or address cyberbullying incidents. Spears and Zeederberg (2012), introduced the concept of online social marketing as a promising intervention strategy which makes use of the internet for preventing cyberbullying to young people. Schools may want to consider employing social media technologies, such as internet forums, social networking sites (e.g. Facebook), blogs and microblogs (i.e. Twitter) as internet platforms to deliver messages especially created for preventing cyberbullying. Those messages could potentially reach students online, which is one of the settings where they are socialising, playing and learning (Spears \& Zeederberg, 2012).

As most young people in developed countries use both the internet and mobile phones (Kleeb, 2007; Netsafe, 2005), there is an elevated risk of experiencing cyberbullying (Livingstone, Haddon, Görzig \& Ólafsson, 2011) which can lead to significant emotional harm. It can disrupt childrens' and adolescents' social development, and it can be associated with negative student outcomes (Kowalski, Limber, \& Agatston, 2008; Marsh et al., 2010). Accordingly, schools must provide students with a safe learning environment. However, schools are challenged with ways to address the phenomenon of cyberbullying, and school staff think they need training to deal with it. As this study has highlighted, the perceptions of school staff can sometimes differ, and as such, the views of senior management need to be taken into consideration to ensure that effective whole-school programmes are implemented and fully-supported.

\section{REFERENCES}

Boulton, M. J. (1997). Teachers' views on bullying: Definitions, attitudes and ability to cope. British Journal of Educational Psychology, 67(2), 223-233.

Calvete, E., Orue, I., Estévez, A.,Villardón, L., \& Padilla, P. (2010). Cyberbullying in adolescents: Modalities and aggressors' profile. Computers in Human Behavior, 26, 1128-11135.

Carroll-Lind, J. (2009). School safety: An inquiry into the safety of students at school. Wellington: Office of the Children's Commissioner. 
Corcoran, L., \& McGuckin, C. (2014). Addressing bullying problems in Irish schools and in cyberspace: A challenge for school management. Educational Research, 56(1), 48-64.

Craig, W. M., Henderson, K., \& Murphy, J. G. (2000). Prospective teachers' attitudes toward bullying and victimization. School Psychology International, 21(1), 5-21.

Cross, D., Shaw, T., Hearn, L., Epstein, M., Monks, H., \& Lester, L. (2009). Australian covert bullying prevalence study (ACBPS). Child Health Promotion Research Centre, Edith Cowan University, Perth, Australia.

Education Counts (n.d.).Retrieved from: https://www.educationcounts.govt.nz/statistics.

Eisenberger, N. I., Lieberman, M. D., \& Williams, K. D. (2003). Does rejection hurt? An fMRI study of social exclusion. Science, 302(5643), pp. 290-292.

Espelage, D. L., Low, S. K., \& Jimerson, S. R. (2014). Understanding school climate, aggression, peer victimization, and bully perpetration: Contemporary science, practice, and policy. School Psychology Quarterly, 29(3), 233-237.

Espelage, D., \& Swearer, S. (2010). A socialecological model for bullying prevention and intervention: Understanding the impact of adults in the social ecology of youngsters. In S. Jimerson, S. Swearer \& D. Espelage (Eds.), Handbook of bullying in schools: An international perspective (pp. 61-72). New York, NY: Routledge.

Green, V A., Mattioni, L., \& Prior, T. (2012). Bullying in New Zealand schools survey. Unpublished manuscript. Wellington, New Zealand: Victoria University of Wellington.

Heiman, T., \& Olenik-Shemesh, D. (2013). Cyberbullying experience and gender differences among adolescents in different educational settings. Journal of Learning Disabilities, 48 (2).

Holt, M., \& Keyes, M. (2004). Teachers' attitudes toward bullying. In D. Espelage \& S. Swearer (Eds.), Bullying in American schools: A social-ecological perspective on prevention and intervention (pp. 121-139). New Jersey: Lawrence Erlbaum Associates, Inc.

Huang, Y. Y., \& Chou, C. (2010). An analysis of multiple factors of cyberbullying among junior high school students in Taiwan. Computers in Human Behavior, 26(6), 1581-1590.
Huang, Y. Y., \& Chou, C. (2013). Revisiting cyberbullying: Perspectives from Taiwanese teachers. Computers \& Education, 63, 227-239.

Johnson, G. M., \& Puplampu, K. P. (2008). Internet use during childhood and the ecological technosubsystem. Canadian Journal of Learning and Technology, 34(1), 19-28.

Kleeb, J. (2007). Youth and the internet: The positives, the challenges and New Zealand developments. Wellington, New Zealand: Victoria University of Wellington.

Kowalski, R. M., Limber, S. P., \& Agatston, P. W. (2008). Cyber bullying: Bullying in the digital age: New York, NY: Blackwell Publishing.

Li, Q. (2008). Cyberbullying in schools: An examination of preservice teachers' perception. Canadian Journal of Learning and Technology, 34(2) 75-90.

Li, Q. (2010). Cyberbullying in high schools: A study of students' behaviors and beliefs about this new phenomenon. Journal of Aggression, Maltreatment \& Trauma, 19(4), 372-392.

Limber, S. P., Kowalski, R. M., \& Agatston, P. W. (2008). Cyber bullying: A prevention curriculum for grades 6-12. Hazelden Publishing.

Livingstone, S., \& Bober, M. (2005). UK children go online: Final report of key project findings 6. London School of Economics and Political Science, London, UK.

Livingstone, S., Haddon, L., Görzig, A., \& Ólafsson, K. (2011). Risks and safety on the internet: The perspective of European children. Full findings. LSE, London, UK: EU Kids Online.

Maher, D. (2008). Cyberbullying: An ethnographic case study of one Australian upper primary school class. Youth Studies Australia, 27(4), 50-57.

Marsh, L., McGee, R., Nada-Raja, S., \& Williams, S. (2010). Brief report: Text bullying and traditional bullying among New Zealand secondary school students. Journal of Adolescence, 33(1), 237-240.

Netsafe (2005). The text generation: Mobile phones and New Zealand youth. Retrieved from www. netsafe.org.nz

Newgent, R. A., Lounsbery, K. L., Keller, E. A., Baker, C. R., Cavell, T. A., \& Boughfman, E. M. (2009). Differential perceptions of bullying in the schools: A comparison of student, parent, teacher, school counselor, and principal reports. Journal of School Counseling, 7, 1-33. 
Oldenburg, B., van Duijn, M., Sentse, M., Huitsing, G., van der Ploeg, R., Salmivalli, C., \& Veenstra, R. (2015). Teacher characteristics and peer victimization in elementary schools: A classroomlevel perspective. Journal of Abnormal Child Psychology, 43(1), 33-44.

Olweus, D. (1997). Bully/victim problems in school: Facts and intervention. European Journal of Psychology of Education, 12(4), 495-510.

Ontario Ministry of Education (2009). School Climate Survey. Retrieved from:

http://www.edu-climate-surveys.ca/english/identify. html?-edit=English

Poulou, M. (2001). The role of vignettes in the research of emotional and behavioural difficulties. Emotional and Behavioural Difficulties, 6(1), 50-62.

Raskauskas, J. L., Gregory, J., Harvey, S. T., Rifshana, F., \& Evans, I. M. (2010). Bullying among primary school children in New Zealand: Relationships with prosocial behaviour and classroom climate. Educational Research, 52(1), 1-13.

Raskauskas, J., \& Stoltz, A. D. (2007). Involvement in traditional and electronic bullying among adolescents. Developmental Psychology, 43(3), 564-575.

Rivers, I., \& Noret, N. (2010). "Ih8 u": Findings from a five year study of text and email bullying. British Educational Research Journal, 36, 643-671.

Salmivalli, C., Sainio, M., \& Hodges, E.V.E. (2013). Electronic victimization: Correlates, antecedents, and consequences among elementary and middle school students. Journal of Clinical Child \& Adolescent Psychology, 42, 442-453.

Salmivalli, C., \& Pöyhonöen, V. (2012). Cyberbullying in Finland. In Q. Li, D. Cross, \& P. Smith. (Eds.). Cyberbullying in the global playground: Research from international perspectives (pp. 57-72). Malden, MA: Blackwell.

Smith, P. K. (2014). Understanding school bullying: Its nature and prevention strategies. London, England: SAGE.

Smith, P. K., Mahdavi, J., Carvalho, M., \& Tippett, N. (2006). An investigation into cyberbullying, its forms, awareness and impact, and the relationship between age and gender in cyberbullying. Research Brief No. RBX03-06. London: DfES.

Smith, P., Mahdavi, J., Carvalho, M., Fisher, S., Russell, S., \& Tippett, N. (2008). Cyberbullying: Its nature and impact in secondary school pupils.
Journal of Child Psychology and Psychiatry, 49(4), 376-385.

Smith, P., \& Slonje, R. (2010). Cyberbullying: The nature and extent of a new kind of bullying. In and out of school. In S. Jimerson, S. Swearer \& D. Espelage (Eds.), Handbook of bullying in schools: An international perspective (pp. 249-262). New York, NY: Routledge.

Smith, P. K., Steffgen, G., \& Sittichai, R. (2013). The nature of cyberbullying, and an international network. In P. K. Smith \& G. Steffgen. (Eds.). (2013). Cyberbullying through the new media: Findings from an international network. (pp. 3-20) Hove, England: Psychology Press.

Spears, B., \& Zeederberg, M. (2012). Emerging methodological strategies to address cyberbullying: Online social marketing and young people as co-researchers. In S. Bauman (Ed.) Principles of Cyberbullying Research: Definitions, Measures \& Methodology. New York, NY: Routledge.

Stauffer, S., Heath, M. A., Coyne, S. M., \& Ferrin, S. (2012). High school teachers' perceptions of cyberbullying prevention and intervention strategies. Psychology in the Schools, 49(4), 352367.

Swearer, S., \& Espelage, D. (2004). Introduction: Social-ecological framework of bullying among youth. In D. Espelage \& S. Swearer (Eds.), Bullying in American schools: A social-ecological perspective on prevention and intervention (pp. 1-12). Mahwah, NJ: Lawrence Erlbaum Associates, Inc.

Tokunaga, R. S. (2010). Following you home from school: A critical review and synthesis of research on cyberbullying victimization. Computers in Human Behavior, 26(3), 277-287.

Wang, J., lannotti, R. J., \& Nansel, T. R. (2009). School bullying among adolescents in the United States: Physical, verbal, relational, and cyber. Journal of Adolescent Health, 45, 368-375.

Ybarra, M. L., \& Mitchell, K. J. (2004). Youth engaging in online harassment: Associations with caregiver-child relationships, internet use, and personal characteristics. Journal of Adolescence, 27(3), 319-336.

Yoon, J. S., \& Kerber, K. (2003). Elementary teachers' attitudes and intervention strategies. Research in Education, 69, 27-35. 


\section{AUTHOR PROFILE}

\section{Loreto Mattioni}

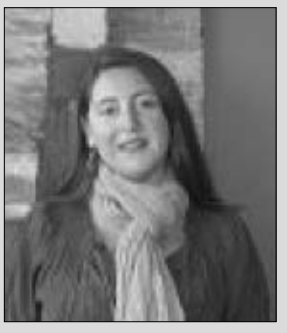

Loreto Mattioni is a clinical psychologist and holds a Master of Education degree from Victoria University of Wellington. Currently works as Assessor at the Ministry of Interior and Public Safety of Chile, in the area of school violence and bullying prevention.

\section{Email:}

I.mattioni@gmail.com
Vanessa A. Green

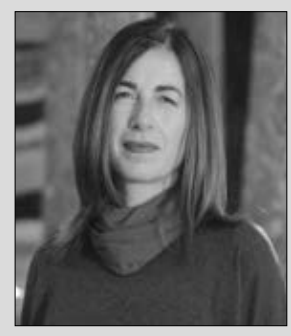

Vanessa A. Green, PhD., is a professor in the School of Education at Victoria University of Wellington. As a developmental psychologist her work within the field of education focuses primarily on the social development of children. She is currently conducting research on the intergenerational nature of bullying and victimisation. She serves on the editorial board of Focus on Autism and Developmental Disabilities and is Associate Editor for Intervention in School and Clinic and International Journal of Disability, Development and Education.

\section{Email:}

Vanessa.Green@vuw.ac.nz

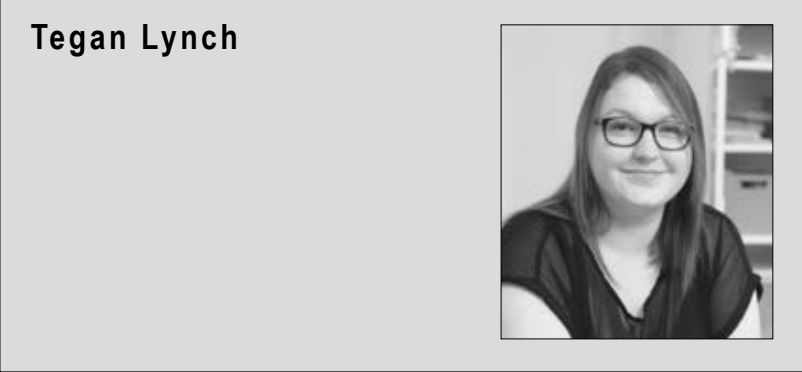

Tegan Lynch is a current PhD student in the School of Education at Victoria University of Wellington, working under the supervision of Professor Vanessa Green and Dr Paul Jose. Her research interests include bullying, particularly relational and cyberbullying, and the impact this can have on families.

\section{Email:}

Tegan.Lynch@vuw.ac.nz

\section{Email:}

flaviu.hodis@vuw.ac.nz 